\title{
Using Exenatide Twice Daily or Insulin in Clinical Practice: Results from CHOICE
}

\author{
Chantal Mathieu • Claes-Göran Östenson - Stephan Matthaei • \\ Matthew Reaney $\cdot$ Thure Krarup $\cdot$ Bruno Guerci $\cdot$ Jacek Kiljański $\cdot$ \\ Carole Salaun-Martin · Hélène Sapin • Michael Theodorakis
}

To view enhanced content go to www.diabetestherapy-open.com

Received: February 20, 2013 / Published online: September 10, 2013

(c) The Author(s) 2013. This article is published with open access at Springerlink.com

\begin{abstract}
Introduction: CHOICE (CHanges to treatment and Outcomes in patients with type 2 diabetes initiating InjeCtable therapy; NCT00635492) assessed, as its primary objective, the time to a 'significant treatment change' (defined within this paper) after patients with type 2 diabetes mellitus initiated their first injectable, glucoselowering therapy [exenatide twice daily (BID) or
\end{abstract}

ClinicalTrials.gov \#NCT0635492.

C. Mathieu ( $\square)$

Department of Endocrinology, UZ Gasthuisberg, 3000 Leuven, Belgium

e-mail: chantal.mathieu@uzleuven.be

C.-G. Östenson

Department of Molecular Medicine and Surgery,

Karolinska Institutet, Stockholm, Sweden

S. Matthaei

Diabetes-Center Quakenbrück, Quakenbrück, Germany

Enhanced content for this article is

available on the journal web site:

www.diabetestherapy-open.com insulin] in clinical practice in six European countries and evaluated outcomes during the study.

Methods: CHOICE was a 24-month, prospective, noninterventional observational study. Patients were invited to participate in CHOICE only after their treating physician had made the clinical decision to initiate first injectable therapy with either exenatide BID or insulin. Clinical data were collected at initiation of first injectable therapy and after approximately 3, 6, 12, 18, and 24 months.

\section{Reaney}

Eli Lilly, Windlesham, Surrey, UK

T. Krarup

Department of Endocrinology I, Bispebjerg Hospital,

Copenhagen, Denmark

B. Guerci

Diabetologie, Maladies Metaboliques \& Nutrition, Hôpital Brabois, CHU de Nancy, et CIC Inserm,

ILCV, 54500 Vandoeuvre Lès Nancy, France

J. Kiljański

Eli Lilly, Warsaw, Poland

C. Salaun-Martin · H. Sapin

Eli Lilly, Neuilly Cedex, France

M. Theodorakis

Department of Clinical Therapeutics, University of Athens School of Medicine, Athens, Greece 
Results: A total of 2,515 patients were recruited; 1,114 patients in the exenatide BID cohort and 1,274 patients in the insulin cohort were eligible for the 24-month analysis. During the study, $42.2 \%$ and $36.0 \%$ of patients from each cohort, respectively, had a significant treatment change. By 24 months, improved mean glycated hemoglobin $(p<0.001$ for both cohorts) and reduced severity of several cardiovascular risk factors were observed in both cohorts; additionally, mean weight was reduced in the exenatide BID cohort $(p<0.001)$ and increased in the insulin cohort $(p<0.001)$. Hypoglycemia was reported by $18.4 \%$ of the exenatide BID cohort and $36.8 \%$ of the insulin cohort; $25.9 \%$ of the exenatide BID cohort and $10.0 \%$ of the insulin cohort had met the secondary endpoint of glycated hemoglobin $<7.0 \%$, no weight gain, and no hypoglycemia.

Conclusion: CHOICE provided data on exenatide BID and insulin usage patterns and 24-month outcomes in clinical practice. On average, improved glycemic control and reduced severity of cardiovascular risk factors were observed in both cohorts, and those in the exenatide BID cohort also had mean weight loss.

Keywords: Diabetes mellitus; Exenatide; Insulin; Injectable therapy; Type 2

\section{INTRODUCTION}

The management of type 2 diabetes mellitus (T2DM) requires a multifactorial treatment approach that addresses clinical and psychosocial aspects of this chronic illness. There are multiple therapeutic classes of oral and injectable treatments available for T2DM. Treatment should be selected and individualized based on specific patient requirements for glycemic control, and patient preferences, characteristics, and susceptibilities to side effects, including potential for weight gain and hypoglycemia [1].

Glucagon-like peptide (GLP)-1 receptor agonists are a relatively new class of medications for T2DM. Randomized clinical trials (RCTs) have shown that exenatide twice daily (BID), the first approved GLP-1 receptor agonist, provided glucose-lowering efficacy similar to that of insulin glargine and biphasic insulin aspart and that, in contrast with insulins, it was associated with weight loss [24]. Although RCTs provide the least biased estimates of efficacy, data derived from a trial setting have limited generalizability to routine clinical practice, where treatment may be initiated in patients dissimilar to those enrolled in the clinical trial program, or it may perform differently than in a controlled setting and where modification of therapy is more common $[5,6]$. In addition, RCTs remove the most important factor affecting the way in which medical care is actually delivered: doctors and patients acting as individuals with differing beliefs, needs, and priorities. Welldesigned prospective observational studies in clinical practice are therefore necessary to provide a holistic understanding of treatment $[7,8]$ and to enhance the evidence upon which the management of T2DM is based [1]. To date, limited information concerning the real-life use of GLP-1 receptor agonists in Europe is available and it is not clear how GLP-1 receptor agonists compare with initial insulin therapy in real life. For example, it has not been clear which patients are prescribed these agents or initial insulin treatment, how long GLP-1 receptor agonists are taken, how patients who eventually stop these agents or modify them by using different combinations of antidiabetes treatments are managed afterwards, and finally, why some patients stop or modify these therapies. Data are limited concerning 
the effectiveness, safety, and associated resource use of both GLP-1 receptor agonists and insulin.

CHOICE (CHanges to treatment and Outcomes in patients with type 2 diabetes initiating InjeCtable therapy; NCT00635492) was a 24-month prospective observational study conducted in multiple European countries. It was designed to assess the time to a significant treatment change after patients initiated their first injectable, glucose-lowering therapy in clinical practice and thereby evaluate patterns of initial injectable therapy usage and outcomes in clinical practice in patients with T2DM. Significant treatment change was defined as at least one of the following: discontinuation of any exenatide BID/insulin initiated at baseline; addition of a new medication (any route of administration) for the treatment of T2DM; a change in the number of times insulin is administered per day; or substitution of a human insulin for an analog insulin or vice versa (not including switching between brands of the same class/type of insulin). Details of the characteristics of patients initiating the two treatment strategies have been described [9]. This paper reports observed treatment changes and clinical outcomes during the study.

\section{PATIENTS AND METHODS}

\section{Design and Patients}

CHOICE is a prospective, multinational, noninterventional observational study that recruited patients from six European countries (Denmark, Belgium, France, Germany, Greece and Sweden) between January 2008 and October 2009. Eligible patients were aged $\geq 18$ years and initiating their first injectable glucose-lowering therapy (with any type of insulin or exenatide BID) for the treatment of T2DM in routine clinical practice. Patients were recruited through 322 investigators (mainly secondary care sites). Patients were invited to participate in CHOICE only after their treating physician had made the clinical decision to initiate either exenatide BID or insulin. Therefore, treatment allocation was not randomized and patients were treated as determined by their physician and, at the time of injectable treatment initiation, were allocated to either the exenatide BID or insulin cohort for analysis purposes. Although exenatide once weekly and liraglutide have more recently been approved, these GLP-1 receptor agonists were not available for routine clinical use at the start of this study and hence were not included for study. At study entry, patients could be taking any oral antidiabetes drugs (OADs).

The primary endpoint was the time from starting the initial injectable regimen (exenatide BID or insulin) to significant treatment change. This endpoint was chosen to meet payer needs for data on duration of treatment with exenatide BID and to generate similar data on insulin treatment.

At baseline (initiation of injectable therapy), standard demographic and clinical data were collected from each patient. At subsequent visits (which occurred as part of routine clinical practice: approximately 3, 6, 12, 18 and 24 months after baseline), changes to injectable therapy, and the time of and reason for the change, were recorded. Follow-up clinical data collected during routine visits included: glycated hemoglobin $\left(\mathrm{HbA}_{1 \mathrm{c}}\right.$; when available and taken from laboratory data obtained as part of routine clinical practice); body weight; waist circumference; body mass index (BMI); fasting lipids; hypoglycemia; gastrointestinal (GI) events (reported only from the 4 weeks preceding each visit); diabetes therapy and care; and concomitant 
medications. Other adverse event data were not routinely collected as part of this study; investigators were instructed to report as they would in normal practice and as required by applicable laws, regulations and practice. Hypoglycemia was reported based on patient recall using no specific definition, except for severe hypoglycemia, which was defined as requiring third-party assistance or a hospital visit.

Patients gave written informed consent for the use of their data and appropriate ethical review board approval was obtained. For more detail on the design of the CHOICE study, see Matthaei et al. [9].

\section{Analysis}

\section{Sample Size Justification}

Monte Carlo simulation was used to calculate sample size, and assumed patient dropout rates of $10-15 \%$ per year and a median time to significant treatment change of 9.0 months for the exenatide BID cohort and 8.6 months for the insulin cohort [10; data on file]. Based on this, the study aimed to recruit a maximum of 800 patients per country/country group, with approximately $60 \%$ initiating insulin and $40 \%$ initiating exenatide BID. The insulin cohort was to be larger than the exenatide BID cohort because of the greater variability in the former cohort (linked to use of different insulin regimens).

\section{Statistical Analysis}

All patients who provided consent to release information, fulfilled the study entry criteria ('eligible patients'), and had a case report form summary page signed by an investigator were included in the analysis. Analyses of the clinical endpoints were conducted on the eligible population in two ways: (1) according to the cohort (insulin or exenatide BID) that they were in at baseline ('initiators analysis'); and (2) using the groups of patients with no significant treatment change (using the original study definitions) at study end or at the time of early discontinuation (this could be at any time) from the study ('persisters analysis'). The persisters analysis was added post hoc due to the observed incidence of treatment changes. Early discontinuation occurred when a patient was lost to follow-up, withdrew from the study, or died at, or before, the 24-month visit.

The primary objective was analyzed using the initiators analysis group. Time to first significant treatment change was estimated using the Kaplan-Meier method for each treatment cohort. If multiple types of change occurred together, the changes were analyzed as occurring in the order presented above. Reasons for the change were summarized using descriptive statistics.

Treatment changes occurring in the insulin cohort were also categorized using an alternative set of definitions that described the intensity and efficacy of the new regimen relative to the starter regimen. This definition considered a significant treatment change to arise if at least one of the following occurred: switch (a change from one insulin regimen to another regimen of similar complexity and similar expected effectiveness); upgrade (a change from one insulin regimen to another of greater complexity or expected effectiveness); downgrade (a change from one insulin regimen to another of lesser complexity or expected effectiveness); discontinuation (the initial insulin regimen is stopped and no further insulin is started within 30 days); initiation of a GLP-1 receptor agonist; and 'other' (this category included changes that could be defined using the original criteria but which 
did not fit within the new criteria); examples of these categories are summarized in Appendix Table 7.

Secondary objectives relating to clinical outcomes data, medication use, and incidence of GI events were reported for the initiators and persisters analysis groups using descriptive statistics for each visit as well as for the change from baseline. Changes in weight and $\mathrm{HbA}_{1 \mathrm{c}}$ over time were explored using Mixed Models for Repeated Measures analyses, controlling for baseline weight/ $/ \mathrm{HbA}_{1 \mathrm{c}}$, propensity score, treatment visit, and the treatment-by-visit interaction.

Propensity score analysis was used to estimate the probability that a patient would be assigned to a treatment group based on baseline characteristics [11]. Scores were derived from baseline data using logistic regression (0.10 threshold for between-cohort differences). Missing data were imputed with the overall mean or median for continuous variables, as well as the most frequent category for categorical variables. Patients were matched 1:1 by country based on the propensity score and optimal matching to identify matched subsets from the two cohorts.

Cox regression models were applied within each cohort to explore the association of baseline characteristics with time to significant treatment change and, post hoc, with the clinically relevant composite secondary endpoint of $\mathrm{HbA}_{1 \mathrm{c}}<7.0 \%$, no weight gain $(\leq 1 \mathrm{~kg})$, and no hypoglycemia [12]. Generalized estimating equation (GEE) models were developed post hoc to explore factors associated with switching treatment (from exenatide BID to insulin, or from any insulin to another insulin regimen of similar complexity and similar expected effectiveness). These models included baseline and timedependent covariates. Baseline variables included microvascular and macrovascular diagnoses, age, gender, and duration of diabetes. Time-fluctuating variables included GI symptoms, hypoglycemic episodes, hospitalizations, and changes in BMI and $\mathrm{HbA}_{1 \mathrm{c}}$. Statistical comparisons of endpoints between the two cohorts were not conducted, as the two treatment cohorts comprised substantially different patient populations (see Matthaei et al. [9]). However, comparative data from a propensity score-derived matched subgroup of the initiators population (exenatide BID vs. insulin) are presented; paired $t$ tests were used to compare changes in continuous variables and McNemar's tests were used to compare categorical variables between the matched subgroups.

\section{RESULTS}

A total of 2,515 patients were recruited; 2,388 (95.0\%) were eligible for the 24-month analysis; 1,114 in the exenatide BID cohort and 1,274 in the insulin cohort (these patients were included in the initiators analyses). Overall, $23.5 \%$ of the eligible patients discontinued the study at or before 24 months (reasons are shown in Fig. 1).

\section{Demographic and Clinical Characteristics}

Overall, patients in the exenatide BID cohort tended to be younger and more obese, but had better glycemic control and fewer diabetes complications compared with the insulin cohort (Table 1) [9].

\section{Treatment Change}

A total of 470 patients from the exenatide BID cohort $(42.2 \%)$ and 459 patients from the insulin cohort (36.0\%) had a significant treatment change during the study. Therefore, 


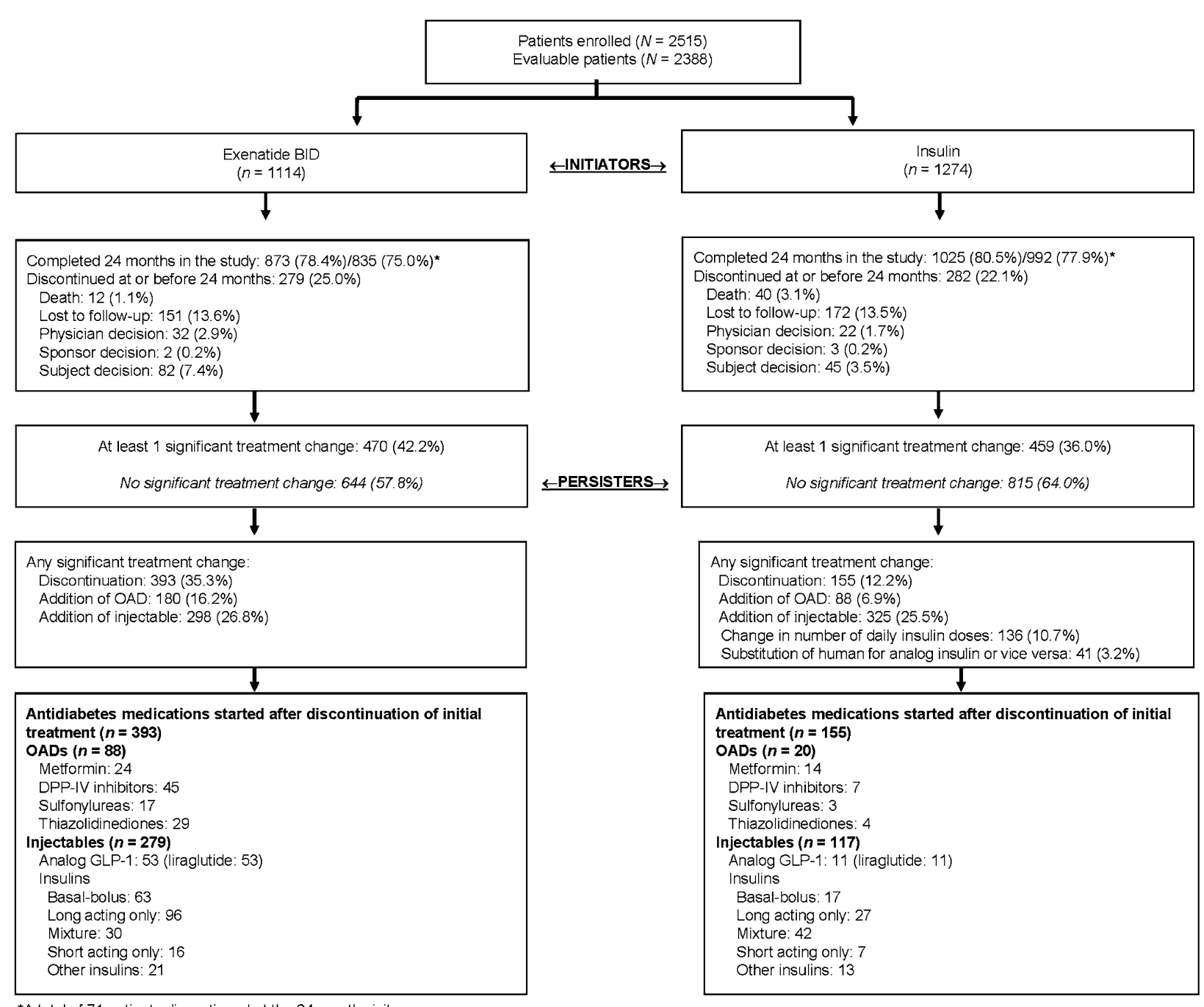

*A total of 71 patients discontinued at the 24 -month visit

Fig. 1 Study disposition at 24 months. BID twice daily, DDP-IV dipeptidyl peptidase-IV, GLP-1 glucagon-like peptide-1, $O A D$ oral antidiabetes drug

644 patients from the exenatide BID cohort $(57.8 \%)$ and 815 patients from the insulin cohort $(64.0 \%)$ were included in the persisters analyses.

In the exenatide BID group, the proportion of enrolled patients experiencing treatment change was highest (20.8\%) in the first 6 months post initiation, and lower thereafter (Fig. 2). Throughout the study, the proportions of patients who had not had a significant treatment change at $6,12,18$ and 24 months were $79.2 \%, 67.8 \%, \quad 59.3 \%$ and $53.9 \%$, respectively. Almost three-fourths of the first significant treatment changes were discontinuations, with the remainder mainly comprising the addition of oral antidiabetes medications (Table 2).

In the insulin cohort, the proportions of enrolled patients who had a significant treatment change was also highest $(22.1 \%)$ in the first 6 months post initiation, and then decreased during the remainder of the study (Fig. 2). Throughout the study, the proportions of patients who had not had significant 
Table 1 Baseline clinical and demographic characteristics of patients with type 2 diabetes mellitus initiated on exenatide BID or insulin therapy

\begin{tabular}{|c|c|c|c|c|}
\hline \multirow[t]{2}{*}{ Variable } & \multicolumn{2}{|l|}{ Initiators } & \multicolumn{2}{|l|}{ Persisters } \\
\hline & $\begin{array}{l}\text { Exenatide BID } \\
(n=1,114)\end{array}$ & $\begin{array}{l}\text { Insulin } \\
(n=1,274)\end{array}$ & $\begin{array}{l}\text { Exenatide BID } \\
(n=644)\end{array}$ & $\begin{array}{l}\text { Insulin } \\
(n=815)\end{array}$ \\
\hline Male $[n(\%)]$ & $598(53.7)$ & $733(57.5)$ & $362(56.2)$ & $470(57.7)$ \\
\hline Age (years) & $58.1(10.1)$ & $63.7(10.9)$ & $58.0(10.1)$ & $63.8(11.0)$ \\
\hline Weight (kg) & $101.2(21.7)$ & $84.2(17.6)$ & $101.1(21.0)$ & $83.7(17.4)$ \\
\hline BMI $\left(\mathrm{kg} / \mathrm{m}^{2}\right)$ & $35.3(6.6)$ & $29.7(5.4)$ & $35.1(6.6)$ & $29.5(5.3)$ \\
\hline \multicolumn{5}{|l|}{ Blood pressure $(\mathrm{mmHg})$} \\
\hline Systolic & $137.7(16.5)$ & $137.4(17.4)$ & $138.1(16.6)$ & $137.5(17.1)$ \\
\hline Diastolic & $81.7(9.6)$ & $80.2(9.9)$ & $82.0(10.0)$ & $80.3(9.8)$ \\
\hline Time since diabetes diagnosis (years) & $8.2(5.7)$ & $9.8(7.3)$ & $8.1(5.2)$ & $9.9(7.5)$ \\
\hline $\mathrm{HbA}_{1 \mathrm{c}}(\%)$ & $8.4(1.4)$ & $9.2(1.9)$ & $8.4(1.4)$ & $9.1(1.9)$ \\
\hline \multicolumn{5}{|l|}{ No. of OADs used $[n(\%)]$} \\
\hline 0 & $76(6.8)$ & $333(26.1)$ & $29(4.5)$ & $64(7.9)$ \\
\hline 1 & $499(44.8)$ & $574(45.1)$ & $220(34.2)$ & $269(33.0)$ \\
\hline 2 & $491(44.1)$ & $341(26.8)$ & $295(45.8)$ & $354(43.4)$ \\
\hline$\geq 3$ & $48(4.3)$ & $26(2.0)$ & $100(15.5)$ & $128(15.7)$ \\
\hline \multicolumn{5}{|l|}{ Insulin regimen $[n(\%)]$} \\
\hline Long-acting only & NA & $627(49.2)$ & NA & $396(48.6)$ \\
\hline Short-acting only & NA & $147(11.5)$ & NA & $57(7.0)$ \\
\hline Pre-mix & NA & $312(24.5)$ & NA & $216(26.5)$ \\
\hline Basal-bolus & NA & $174(13.7)$ & NA & $137(16.8)$ \\
\hline Other & NA & $14(1.1)$ & NA & $9(1.1)$ \\
\hline $\begin{array}{l}\text { Patients with } \geq 1 \text { hypoglycemic event } \\
\text { (in past } 3 \text { months) }[n(\%)]^{a}\end{array}$ & $59(5.3)$ & $56(4.4)$ & $33(5.1)$ & $28(3.4)$ \\
\hline \multicolumn{5}{|l|}{ Diabetes complications $[n(\%)]$} \\
\hline$\geq 1$ macrovascular complication & $200(18.0)$ & $320(25.1)$ & $120(18.6)$ & $202(24.8)$ \\
\hline$\geq 1$ microvascular complication & $164(14.7)$ & $263(20.6)$ & $91(14.1)$ & $151(18.5)$ \\
\hline
\end{tabular}

Continuous data are means $(\mathrm{SD})$

$B I D$ twice daily, $B M I$ body mass index, $H b A_{1 c}$ glycated hemoglobin, $N A$ not applicable, $O A D$ oral antidiabetes drug, $S D$ standard deviation

${ }^{a}$ Incidence is based on patient recall of events occurring during the past 3 months

treatment change at $6,12,18$ and 24 months were $77.9 \%, 70.6 \%, 64.9 \%$ and $60.6 \%$, respectively. The most common first significant treatment change for insulin patients was the addition of a new injectable antidiabetes medication $(45.3 \%$ of first 


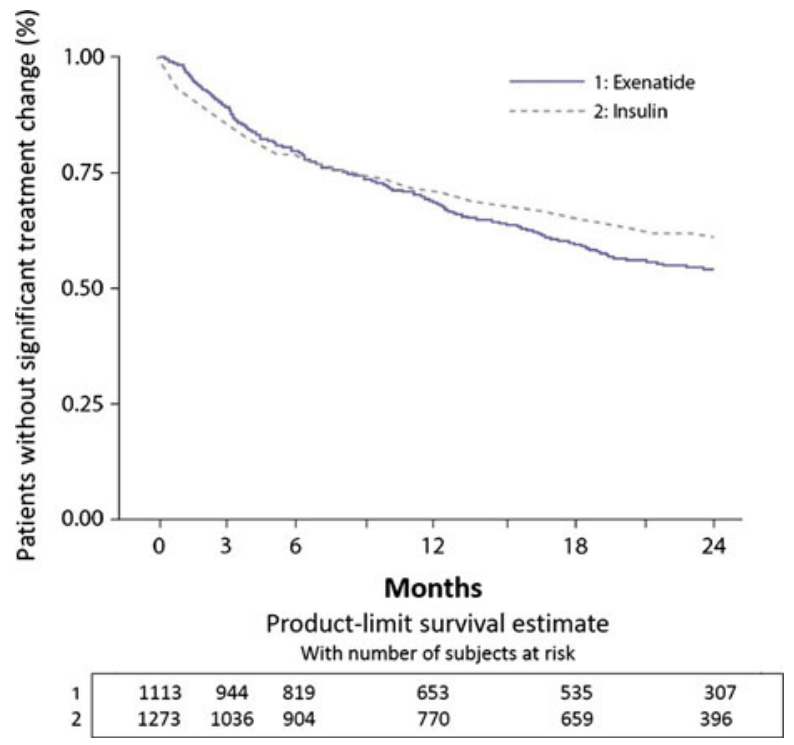

Fig. 2 Kaplan-Meier estimates for time until significant treatment change after initiation of injectable therapy with exenatide BID or insulin. BID twice daily

significant treatment changes; Table 2). When changes in the insulin cohort were considered using the alternative definition of treatment change (i.e., describing the intensity and efficacy of the new regimen relative to the starter regimen), $0.6 \%$ added a GLP-1 receptor agonist, $0.5 \%$ switched the type of insulin they were using, $16.5 \%$ upgraded therapy, $0.2 \%$ downgraded therapy, $\quad 7.7 \%$ discontinued therapy, and $10.5 \%$ had 'other' changes. The first significant treatment changes by insulin type are presented in Fig. 3.

Throughout the 24-month observation period, 393 patients (35.3\%) in the exenatide BID cohort and 155 patients (12.2\%) in the insulin cohort discontinued at least one baseline injectable therapy. For 170 patients in the exenatide BID cohort (15.3\%) and 87 patients in the insulin cohort (6.8\%) this was because of inadequate response (Table 3 ). Other reasons for discontinuation are summarized in Table 3. Of the 393 patients from the exenatide BID cohort, 10 patients (2.5\%) did not start anything else, 373 (94.9\%) started an (additional) OAD, 53 (13.5\%) started liraglutide, and 283 (72.0\%) started insulin. Of

Table 2 First significant treatment change occurring during the 24 months following initiation of exenatide BID or insulin in patients with type 2 diabetes mellitus

\begin{tabular}{|c|c|c|}
\hline Variable & $\begin{array}{l}\text { Exenatide BID } \\
(n=1,114)\end{array}$ & $\begin{array}{l}\text { Insulin } \\
(n=1,274)\end{array}$ \\
\hline At least one significant treatment change $[n(\%)]$ & $470(42.2)$ & $459(36.0)$ \\
\hline \multicolumn{3}{|l|}{ First significant treatment change $[n(\%)]^{\mathrm{a}}$} \\
\hline Discontinuation of any injectable medication initiated at baseline & $349(31.3)$ & $111(8.7)$ \\
\hline $\begin{array}{l}\text { Addition of a new medication (any route of administration) for the treatment } \\
\text { of type } 2 \text { diabetes }\end{array}$ & $121(10.9)$ & $267(21.0)$ \\
\hline Addition of a new oral medication & $102(9.2)$ & $59(4.6)$ \\
\hline Addition of a new injectable medication & $19(1.7)$ & $208(16.3)$ \\
\hline Change to the number of times insulin was administered per day & NA & $81(6.4)$ \\
\hline Substitution of a human insulin for an analog insulin or vice versa & NA & $0(0)$ \\
\hline
\end{tabular}

$B I D$ twice daily, $N A$ not applicable

a Where two categories of significant treatment change occurred simultaneously, the categories were ordered: (1) discontinuation of any injectable medication initiated at baseline; (2) addition of new medication; (3) change to the number of times insulin was administered per day; (4) substitution of a human insulin for an analog insulin or vice versa 


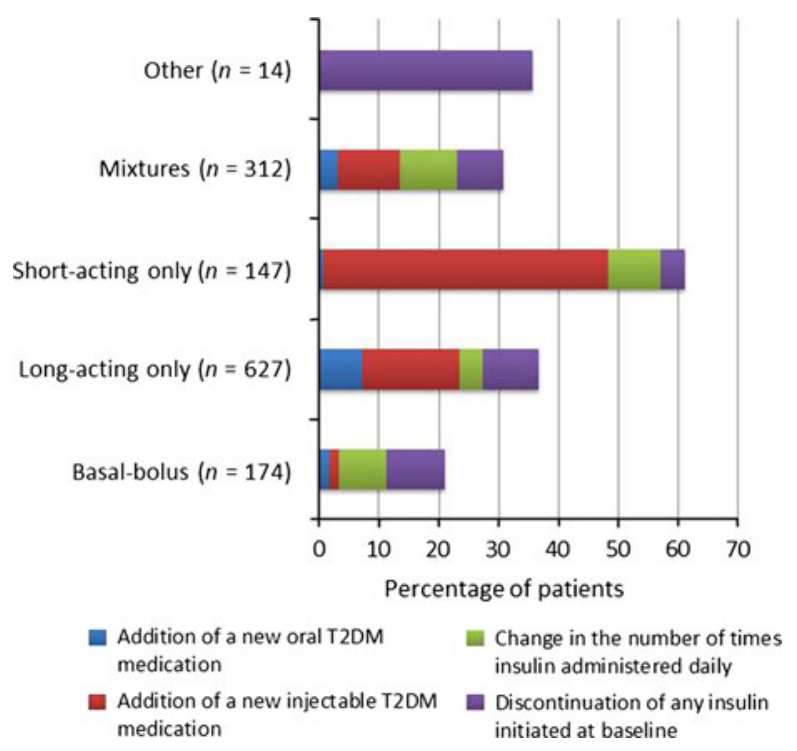

Fig. 3 First significant treatment change (using the primary definition) occurring during the 24 months following initiation of insulin in patients with T2DM according to baseline insulin regimen (the 'other' category comprised combinations of a 'mixture' with either a 'short-acting' or 'long-acting' insulin). T2DM type 2 diabetes mellitus

the 155 patients from the insulin cohort who discontinued their baseline insulin, 18 patients (11.6\%) did not start anything else, 41 (26.5\%) switched a human insulin for an analog insulin, or vice versa, 21 (13.5\%) started an (additional) OAD, 11 (7.1\%) started liraglutide, and 106 (68.4\%) started a new insulin. In addition, $18.2 \%$ of the exenatide BID cohort and 13.1\% of the insulin cohort discontinued their baseline OADs. All antidiabetes medications added or discontinued throughout the study are presented in Table 4.

Cox proportional hazards models, performed to investigate the impact of baseline medications and patient clinical characteristics on time to significant treatment changes, indicated that there was nothing of clinical relevance in either treatment cohort. In the exenatide BID cohort, the final Cox proportional hazards model identified the occurrence of GI symptoms reported in the last 4 weeks prior to initiation of injectable treatment to be statistically significantly associated with a higher risk of significant treatment change [hazard ratio (HR) $1.564 ; p=0.007)]$. In the insulin cohort, the final Cox proportional hazards model identified the following factors to be significantly associated with a higher risk of significant treatment change: higher baseline $\mathrm{HbA}_{1 \mathrm{c}}$ (HR 1.121; $p<0.001$ ), the occurrence of GI symptoms in the last 4 weeks prior to initiation of injectable treatment (HR 2.040; $p<0.001$ ), and the type of insulin initiated. When compared with baseline initiation of long-acting insulin only, patients initiating basal-bolus insulin (HR 0.530; $p<0.001$ ) or mixtures (HR 0.762; $p=0.026$ ) were less likely, whereas those initiating shortacting insulin only were more likely (HR 2.373; $p<0.001$ ) to have a significant treatment change.

The post hoc GEE model showed that in the exenatide BID cohort, switching from exenatide BID to insulin therapy was more likely among patients who had an increase in BMI [no vs. yes, odds ratio (OR) $0.464 ; p<0.001$ ] or $\mathrm{HbA}_{1 \mathrm{c}}$ (no vs. yes, OR $0.731 ; p<0.001)$ over the duration of treatment. There was no evidence for an association between baseline characteristics and this switch. The observed incidence of changing the baseline insulin regimen (as per the primary endpoint) was higher in patients who had an increase in BMI (no vs. yes, OR 0.705; $p<0.001$ ), increase in $\mathrm{HbA}_{1 \mathrm{c}}$ (no vs. yes, OR 0.645; $p<0.0001$ ), or who experienced hypoglycemia (OR 0.691; $p<0.001$ ) over the duration of treatment. Baseline microvascular diagnoses $(\geq 1)$ were also associated with changes in insulin regimen (no vs. yes, OR 0.656; $p<0.01$ ).

\section{Clinical Outcomes and Adverse Events}

\section{Exenatide BID}

Improvements were observed in $\mathrm{HbA}_{1 \mathrm{c}}$ in the exenatide BID cohort (Table 5). When 


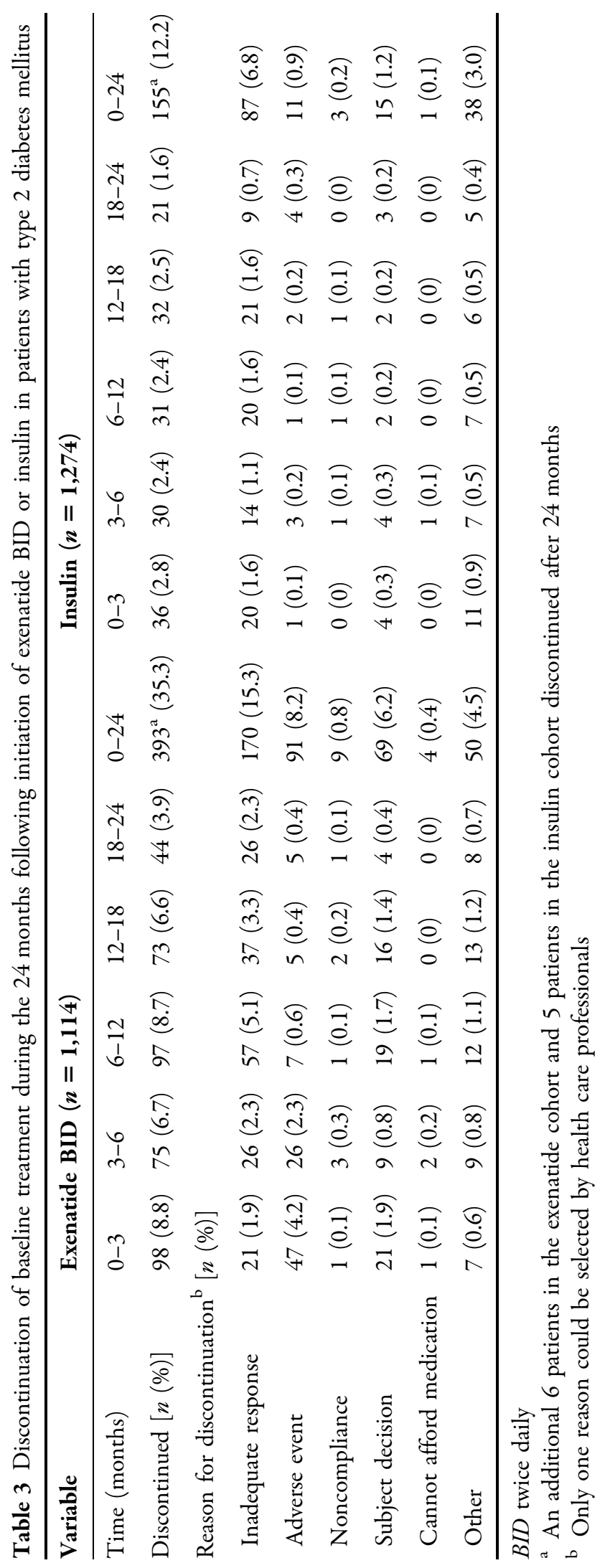


Table 4 Antidiabetes medications added or discontinued during the 24 months following initiation of exenatide BID or insulin in patients with type 2 diabetes mellitus

\begin{tabular}{|c|c|c|c|c|}
\hline \multirow[t]{2}{*}{ Variable } & \multicolumn{2}{|c|}{ Exenatide BID $(n=1,114)$} & \multicolumn{2}{|c|}{ Insulin $(n=1,274)$} \\
\hline & $\begin{array}{l}\text { Between } \\
\text { baseline and } \\
24 \text { months }\end{array}$ & $\begin{array}{l}\text { Added within } \\
6 \text { weeks of first } \\
\text { significant } \\
\text { treatment change }\end{array}$ & $\begin{array}{l}\text { Between } \\
\text { baseline and } \\
24 \text { months }\end{array}$ & $\begin{array}{l}\text { Added within } \\
6 \text { weeks of first } \\
\text { significant } \\
\text { treatment change }\end{array}$ \\
\hline $\begin{array}{l}\text { Injectable antidiabetes } \\
\text { therapy added }[n(\%)]\end{array}$ & $298(26.8)$ & $257(23.1)$ & $325(25.5)$ & $298(23.4)$ \\
\hline \multicolumn{5}{|l|}{ Insulin } \\
\hline Long-acting & $159(14.3)$ & $126(11.3)$ & $82(6.4)$ & $63(4.9)$ \\
\hline Intermediate-acting & $61(5.5)$ & $45(4.0)$ & $62(4.9)$ & $55(4.3)$ \\
\hline Fast/short-acting & $92(8.3)$ & $54(4.8)$ & $148(11.6)$ & $117(9.2)$ \\
\hline Mixtures & $60(5.4)$ & $41(3.7)$ & $88(6.9)$ & $76(6.0)$ \\
\hline Exenatide & $0(0)$ & $0(0)$ & $2(0.2)$ & $0(0)$ \\
\hline Liraglutide & $53(4.8)$ & $34(3.1)$ & $15(1.2)$ & $8(0.6)$ \\
\hline $\begin{array}{l}\text { Injectable antidiabetes therapy } \\
\text { discontinued }[n(\%)]\end{array}$ & $396(35.5)$ & NA & $170(13.3)$ & NA \\
\hline \multicolumn{5}{|l|}{ Insulin } \\
\hline Long-acting & $18(1.6)$ & NA & $67(5.3)$ & NA \\
\hline Intermediate-acting & $13(1.2)$ & NA & $50(3.9)$ & NA \\
\hline Fast-acting & $6(0.5)$ & NA & $40(3.1)$ & NA \\
\hline Mixtures & $7(0.6)$ & NA & $51(4.0)$ & NA \\
\hline Exenatide & $393(35.3)$ & NA & $0(0)$ & NA \\
\hline Liraglutide & $8(0.7)$ & NA & $1(0.1)$ & NA \\
\hline OADs added $[n(\%)]$ & $180(16.2)$ & $158(14.2)$ & $88(6.9)$ & $65(5.1)$ \\
\hline \multicolumn{5}{|l|}{ Insulin } \\
\hline Alpha-glucosidase inhibitors & $4(0.4)$ & $4(0.4)$ & $3(0.2)$ & $1(0.1)$ \\
\hline DPP-IV inhibitor & $41(3.7)$ & $28(2.5)$ & $18(1.4)$ & $10(0.8)$ \\
\hline Metformin & $32(2.9)$ & $30(2.7)$ & $23(1.8)$ & $18(1.4)$ \\
\hline SU & $63(5.7)$ & $53(4.8)$ & $21(1.6)$ & $15(1.2)$ \\
\hline Meglitinide & $21(1.9)$ & $14(1.3)$ & $17(1.3)$ & $15(1.2)$ \\
\hline TZD & $29(2.6)$ & $24(2.2)$ & $9(0.7)$ & $5(0.4)$ \\
\hline Metformin and DPP-IV inhibitor & $5(0.4)$ & $3(0.2)$ & $5(0.4)$ & $1(0.1)$ \\
\hline Metformin and SU & $5(0.4)$ & $4(0.4)$ & $0(0)$ & $0(0)$ \\
\hline Metformin and TZD & $10(0.9)$ & $6(0.5)$ & $2(0.2)$ & $2(0.2)$ \\
\hline Other & $0(0)$ & $0(0)$ & $2(0.2)$ & $1(0.1)$ \\
\hline
\end{tabular}


Table 4 continued

\begin{tabular}{|c|c|c|c|c|}
\hline \multirow[t]{2}{*}{ Variable } & \multicolumn{2}{|c|}{ Exenatide BID $(n=1,114)$} & \multicolumn{2}{|c|}{ Insulin $(n=1,274)$} \\
\hline & $\begin{array}{l}\text { Between } \\
\text { baseline and } \\
24 \text { months }\end{array}$ & $\begin{array}{l}\text { Added within } \\
6 \text { weeks of first } \\
\text { significant } \\
\text { treatment change }\end{array}$ & $\begin{array}{l}\text { Between } \\
\text { baseline and } \\
24 \text { months }\end{array}$ & $\begin{array}{l}\text { Added within } \\
6 \text { weeks of first } \\
\text { significant } \\
\text { treatment change }\end{array}$ \\
\hline OADs discontinued $[n(\%)]$ & $358(32.1)$ & NA & $545(42.8)$ & NA \\
\hline \multicolumn{5}{|l|}{ Insulin } \\
\hline Alpha-glucosidase inhibitors & $14(1.3)$ & NA & $12(0.9)$ & NA \\
\hline DPP-IV inhibitor & $67(6.0)$ & NA & $62(4.9)$ & NA \\
\hline Metformin & $60(5.4)$ & NA & $140(11.0)$ & NA \\
\hline SU & $188(16.9)$ & NA & $350(27.5)$ & NA \\
\hline Meglitinide & $48(4.3)$ & NA & $48(3.8)$ & NA \\
\hline TZD & $75(6.7)$ & NA & $78(6.1)$ & NA \\
\hline TZD and SU & $0(0)$ & NA & $1(0.1)$ & NA \\
\hline Metformin and SU & $5(0.4)$ & NA & $14(1.1)$ & NA \\
\hline Metformin and TZD & $36(3.2)$ & NA & $21(1.6)$ & NA \\
\hline Other & $1(0.1)$ & NA & $1(0.1)$ & NA \\
\hline
\end{tabular}

Patients could add/discontinue more than 1 treatment throughout the study

$B I D$ twice daily, $D P P-I V$ dipeptidyl peptidase-IV, $N A$ not applicable, $O A D$ oral antidiabetes drug, $S U$ sulfonylurea, $T Z D$ thiazolidinedione

controlling for baseline $\mathrm{HbA}_{1 \mathrm{c}}$, treatment and visit, statistically significant improvements in glycemic control were observed over the course of the study in the exenatide BID initiator population $(p<0.001)$. Mean (standard deviation, SD) $\mathrm{HbA}_{1 \mathrm{c}}$ was $8.4(1.4) \%$ units at baseline, $7.5(1.2) \%$ units at 3 months, and remained between $7.3 \quad(1.2) \%$ units and $7.4(1.2) \%$ units at each further visit.

Improvements were also seen in mean values of variables for a number of other cardiovascular risk factors, including blood pressure and lipid parameters (Table 5). In addition, mean weight was significantly reduced in the exenatide BID cohort by 24 months (Table $5 ; p<0.001$ ). Weight loss $(>1.0 \mathrm{~kg})$ was achieved by $62.2 \%$ of initiators and $72.5 \%$ of persisters in the exenatide BID cohort. In the initiators group, mean (SD) baseline weight was $101.2(21.8) \mathrm{kg}$; at 3 months, this was 98.7 (21.7) $\mathrm{kg}$ and at each further visit, mean weight remained between 97.7 (20.8) $\mathrm{kg}$ and 98.3 (21.3) kg. In the exenatide BID persisters group, mean weight decreased until month 18 and remained below baseline levels for the remainder of the study.

Overall, $18.4 \%$ of patients who initiated exenatide BID $\quad(15.7 \%$ of persisters $)$ experienced at least one episode of hypoglycemia. The majority of episodes occurred in patients receiving concomitant sulfonylureas (Fig. 4). Severe hypoglycemia (requiring third-party assistance or a hospital 


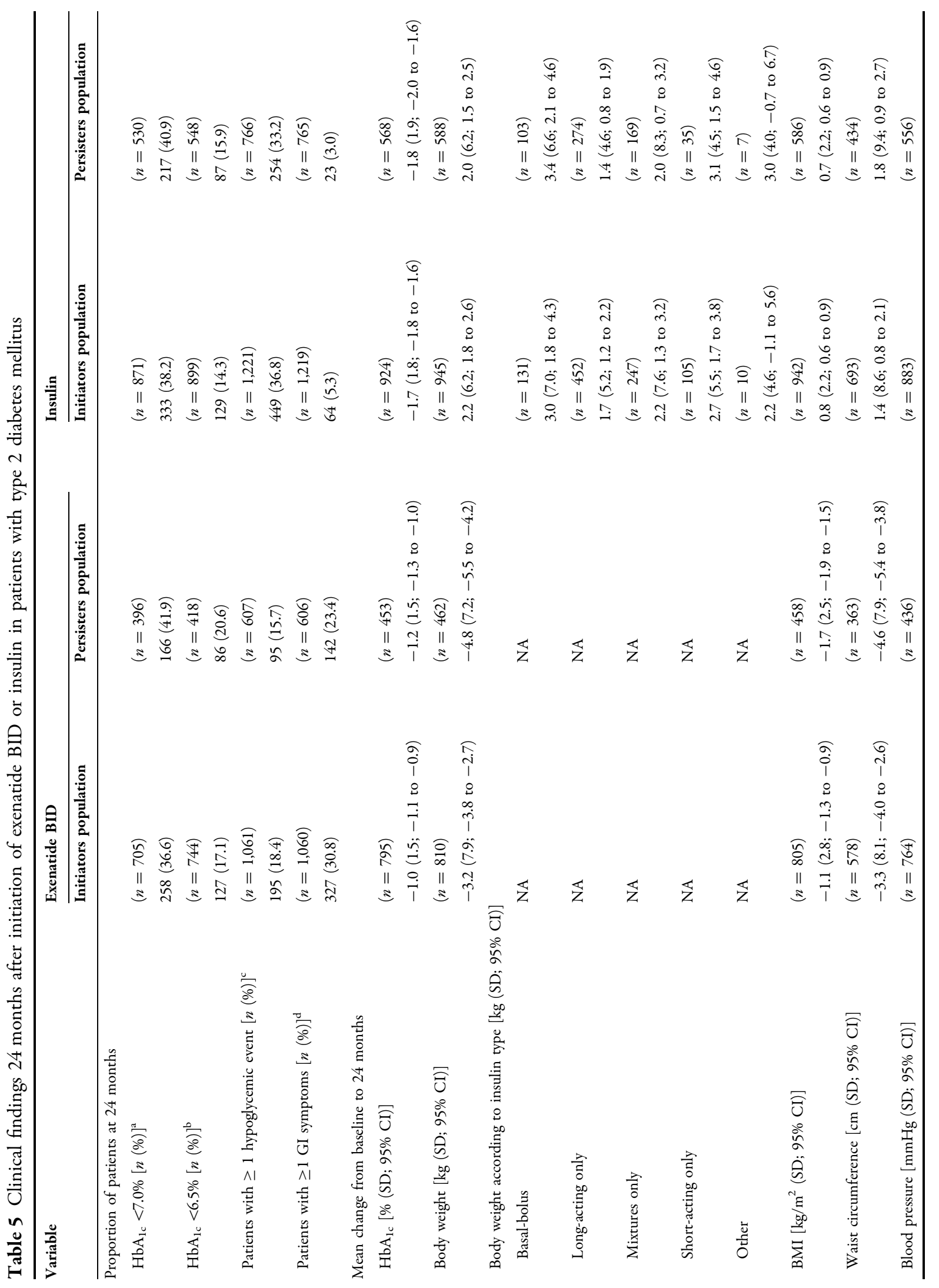




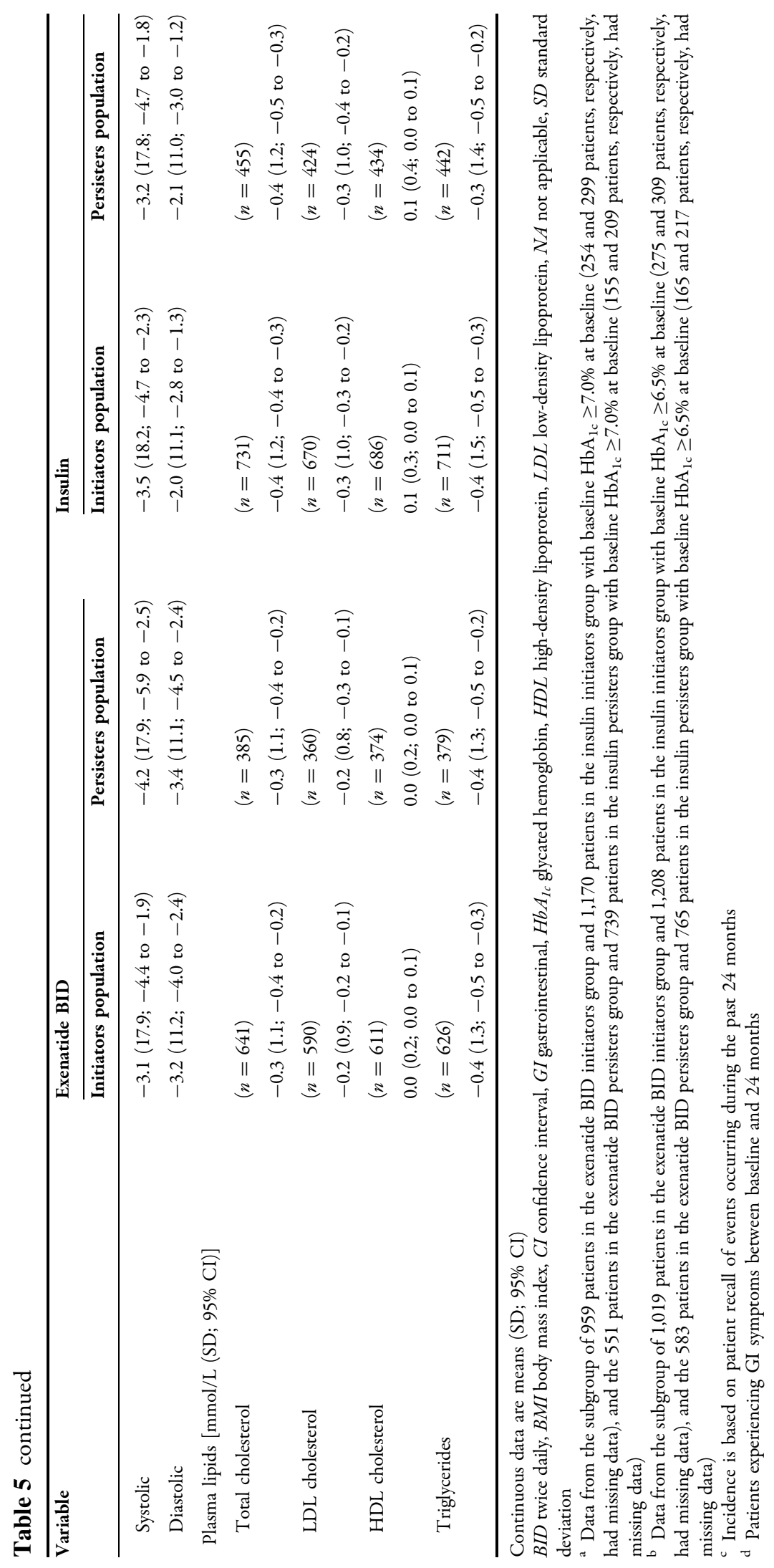




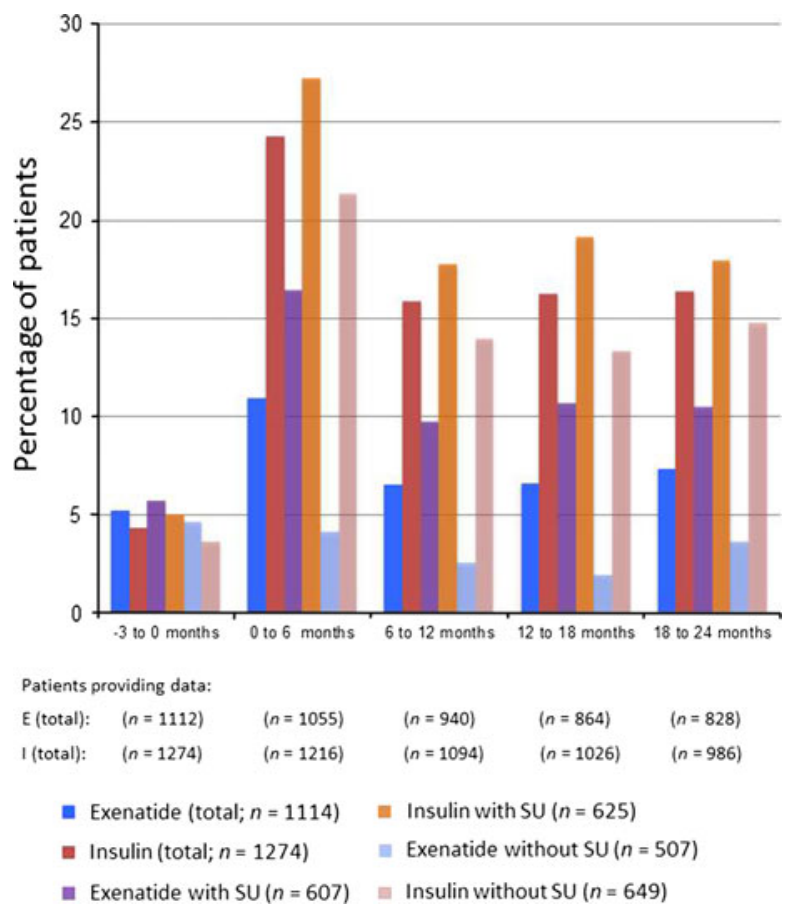

Fig. 4 Proportion of patients with T2DM reporting hypoglycemia per 6-month period in the exenatide BID (E) and insulin (I) cohorts, overall and according to use of SUs; initiators analysis. SU use was defined as any use of SU during the study, irrespective of whether use was interrupted or discontinued. BID twice daily, $S U$ sulfonylurea, $T 2 D M$ type 2 diabetes mellitus

visit) was experienced by $1.2 \%$ of exenatide BID initiators (11 patients) and $1.1 \%$ of persisters (6 patients). During the 3 months before the baseline visit, the exenatide BID cohort had experienced a mean (SD) of 0.4 (5.7) hypoglycemic events. During the study, patients in this cohort experienced a mean (SD) of 1.3 (5.4) hypoglycemic events.

At 24 months, the proportion of patients who met the composite endpoint of $\mathrm{HbA}_{1 \mathrm{c}}$ $<7.0 \%$, no weight gain ( $\leq 1 \mathrm{~kg}$ change), and no hypoglycemia was $25.9 \%$ and $32.2 \%$ in the exenatide BID initiator and persister populations, respectively. A shorter duration of diabetes $(p=0.002)$ and lower $\mathrm{HbA}_{1 \mathrm{c}}$ $(p<0.001)$ were associated with achievement of this outcome in the exenatide BID cohort.
Overall, $30.8 \%$ of the exenatide BID cohort experienced GI events; most commonly, nausea (16.8\% of patients). The number of patients with GI events was higher in the first 6 months $(26.2 \%$ of patients with data) than in all subsequent 6-month periods $(<8 \%$ of patients with data; events were reported from the 4 weeks prior to each visit only).

\section{Insulin}

Improvements were observed in $\mathrm{HbA}_{1 \mathrm{c}}$ in the insulin cohort (Table 5). When controlling for baseline $\mathrm{HbA}_{1 \mathrm{c}}$, treatment and visit, statistically significant improvements in glycemic control were observed over the course of the study in the insulin initiator population $(p<0.001)$. Mean (SD) $\mathrm{HbA}_{1 \mathrm{c}}$ values were 9.2 (1.9)\% units at baseline, $7.5(1.4) \%$ units at 3 months, and between 7.3 (1.0)\% units and 7.3 (1.1)\% units for the remainder of the study period.

Improvements were also seen in mean values of variables for a number of other cardiovascular risk factors, including blood pressure and lipid parameters (Table 5). However, mean weight was significantly increased in the insulin cohort (Table 5; $p<0.001$ ). Overall, $58.7 \%$ of insulin initiators and $57.3 \%$ of persisters gained weight $(>1.0 \mathrm{~kg})$, with mean weight tending to increase throughout the entire study for both initiators and persisters. In the initiators group, mean (SD) baseline weight was $84.2(17.6) \mathrm{kg}$; at 3 months, mean weight was 84.9 (17.3) kg and at each further visit, mean weight was between $85.6(17.4) \mathrm{kg}$ and 86.7 (17.8) kg.

Overall, $36.8 \%$ of patients who initiated insulin (33.3\% of persisters) experienced at least one episode of hypoglycemia (Fig. 4). Severe hypoglycemia (requiring third-party assistance or a hospital visit) was experienced by $8.4 \%$ of insulin initiators (76 patients) and $5.7 \%$ of persisters (34 patients). During the 3 months before the baseline visit, patients in 
the insulin cohort had experienced a mean (SD) of 0.2 (2.3) hypoglycemic events. During the study, patients in this cohort experienced a mean (SD) of 3.7 (14.2) hypoglycemic events.

At 24 months, the proportion of patients who met the clinically relevant composite endpoint of $\mathrm{HbA}_{1 \mathrm{c}}<7.0 \%$, no weight gain ( $\leq 1 \mathrm{~kg}$ change), and no hypoglycemia was $10.0 \%$ and $11.8 \%$ in the insulin initiator and persister populations, respectively. A shorter duration of diabetes $(p<0.001)$, lower $\mathrm{HbA}_{1 \mathrm{c}}$ $(p<0.001)$, lower diastolic blood pressure $(p=0.050)$, higher BMI $(p=0.002)$, the absence of GI symptoms $(p=0.005)$, and initial insulin regimen (mixtures versus basal only; $p=0.004)$ were associated with achievement of the composite endpoint.

Overall, $5.3 \%$ of patients in the insulin cohort experienced GI events (most commonly abdominal pain in $2.5 \%$ of patients).

\section{Propensity-Matched Subgroup}

Propensity matching of baseline patient and disease characteristics identified 619 pairs of patients who could be compared $(51.8 \%$ of the total sample). These patients had a mean (SD) duration of diabetes of 9.1 (6.3) years [9.0 (6.0) years for the exenatide BID group and 9.2 (6.6) years for the insulin group]; other baseline characteristics are summarized in Table 6. In this propensity-matched subgroup, patients in the exenatide BID group had significantly greater mean (SD) weight loss $(p<0.0001)$ and a lower incidence of patientrecalled hypoglycemia $(p<0.0001)$ than the insulin group during the study (Table 6). However, there was no significant difference between treatment groups regarding mean (SD) change in $\mathrm{HbA}_{1 \mathrm{c}}$ or in the percentages of patients at 24 months with $\mathrm{HbA}_{1 \mathrm{c}}<7.0 \%$ or $<6.5 \%$. At 24 months, the proportion of patients who met the composite endpoint of
$\mathrm{HbA}_{1 \mathrm{c}}<7.0 \%$, no weight gain ( $\leq 1 \mathrm{~kg}$ change), and no hypoglycemia was $26.9 \%$ in the exenatide BID group and $11.0 \%$ in the insulin group ( $p<0.0001$, McNemar's test) (post hoc analysis).

\section{DISCUSSION}

CHOICE was a prospective observational study designed to evaluate patterns of exenatide BID and insulin usage and outcomes in clinical practice in multiple European countries. In this study, $42.2 \%$ of patients who initiated exenatide BID and 36.0\% who initiated insulin had a significant treatment change during the 24 months after these treatments were started. In another European study of insulin initiation [13], rates of treatment change in the 24-month period following insulin initiation were 2.9-19.4\% (depending on insulin regimen). It is unclear why the results of that study differed from our findings. In CHOICE, patients in the two treatment cohorts were substantially different, with the exenatide BID cohort tending to have a younger age, higher body weight, BMI, waist circumference and diastolic blood pressure, lower total and low-density lipoprotein (LDL)-cholesterol levels, a shorter time since diabetes diagnosis, and better glycemic control at baseline than patients in the insulin cohort [9]. Therefore, we were unable to compare the clinical findings for the total exenatide BID and insulin cohorts.

Time to significant treatment change was chosen as the primary outcome of this study, because it was anticipated that patients prescribed exenatide BID would continue to move through the available treatment algorithms until insulin was initiated. A combination of factors, including glycemic control and tolerability, were believed to influence treatment changes or 
Table 6 Baseline and 24-month clinical data for patients initiated on exenatide BID or insulin therapy: a propensity score subpopulation analysis

\begin{tabular}{|c|c|c|c|c|c|}
\hline \multirow[t]{2}{*}{ Variable } & \multicolumn{2}{|c|}{$\begin{array}{l}\text { Exenatide BID } \\
(n=619)\end{array}$} & \multicolumn{2}{|c|}{ Insulin $(n=619)$} & \multirow[t]{2}{*}{$\begin{array}{l}p \text { value } \\
\text { (change) }\end{array}$} \\
\hline & Baseline & 24 months & Baseline & 24 months & \\
\hline \multirow[t]{2}{*}{ Weight (kg) } & $(n=618)$ & $(n=448)$ & $(n=615)$ & $(n=474)$ & \\
\hline & $93.2(18.1)$ & $90.8(18.7)$ & $91.8(18.1)$ & $93.8(18.4)$ & - \\
\hline \multirow[t]{2}{*}{ Change in weight $(\mathrm{kg})$} & & $(n=448)$ & & $(n=472)$ & \\
\hline & & $-2.8(6.6)$ & & $1.5(6.6)$ & $<0.0001$ \\
\hline \multicolumn{6}{|l|}{ Blood pressure $(\mathrm{mmHg})$} \\
\hline \multirow[t]{2}{*}{ Systolic } & $(n=615)$ & $(n=425)$ & $(n=612)$ & $(n=442)$ & \\
\hline & $137.2(16.7)$ & $133.7(14.5)$ & $137.5(16.5)$ & $134.0(15.0)$ & - \\
\hline \multirow[t]{2}{*}{ Change in systolic } & & $(n=422)$ & & $(n=437)$ & \\
\hline & & $-3.6(17.5)$ & & $-3.1(16.4)$ & 0.3783 \\
\hline \multirow[t]{2}{*}{ Diastolic } & $(n=615)$ & $(n=425)$ & $(n=612)$ & $(n=442)$ & \\
\hline & $81.1(9.3)$ & $77.5(9.6)$ & $80.9(10.0)$ & $79.1(8.8)$ & - \\
\hline \multirow[t]{2}{*}{ Change in diastolic } & & $(n=422)$ & & $(n=437)$ & \\
\hline & & $-3.7(11.2)$ & & $-1.5(10.6)$ & 0.0017 \\
\hline \multirow[t]{2}{*}{$\mathrm{HbA}_{1 \mathrm{c}}(\%)$} & $(n=600)$ & $(n=452)$ & $(n=604)$ & $(n=473)$ & \\
\hline & $8.7(1.5)$ & $7.3(1.1)$ & $8.6(1.5)$ & $7.3(1.1)$ & - \\
\hline \multirow[t]{2}{*}{ Change in $\mathrm{HbA}_{1 \mathrm{c}}(\%)$} & & $(n=443)$ & & $(n=463)$ & \\
\hline & & $-1.3(1.5)$ & & $-1.2(1.5)$ & 0.8473 \\
\hline \multirow[t]{2}{*}{$\mathrm{HbA}_{1 \mathrm{c}}<7.0 \%[n(\%)]^{\mathrm{a}}$} & $(n=600)$ & $(n=411)$ & $(n=604)$ & $(n=420)$ & \\
\hline & $45(7.5)$ & $165(40.1)$ & $56(9.3)$ & $154(36.7)$ & - \\
\hline \multirow[t]{2}{*}{$\mathrm{HbA}_{1 \mathrm{c}}<6.5 \%[n(\%)]^{\mathrm{b}}$} & $(n=600)$ & $(n=421)$ & $(n=604)$ & $(n=441)$ & \\
\hline & $30(5.0)$ & $69(16.4)$ & $28(4.6)$ & $67(15.2)$ & - \\
\hline \multirow[t]{2}{*}{ Patients with $\geq 1$ hypoglycemic event $[n(\%)]^{\mathrm{c}}$} & $(n=619)$ & $(n=590)$ & $(n=619)$ & $(n=597)$ & \\
\hline & $35(5.7)$ & $120(20.3)^{*}$ & $30(4.8)$ & $199(33.3)$ & - \\
\hline \multirow[t]{2}{*}{ Patients with $\geq 1$ GI symptoms, $[n(\%)]^{\mathrm{d}}$} & $(n=618)$ & $(n=590)$ & $(n=619)$ & $(n=597)$ & \\
\hline & $30(4.9)$ & $182(30.8)^{*}$ & $30(4.8)$ & $35(5.9)$ & - \\
\hline \multicolumn{6}{|l|}{ Lipids (mmol/L) } \\
\hline \multirow[t]{2}{*}{ Total cholesterol } & $(n=561)$ & $(n=336)$ & $(n=551)$ & $(n=381)$ & \\
\hline & $5.0(1.0)$ & $4.7(1.0)$ & $5.0(1.1)$ & $4.8(1.0)$ & - \\
\hline \multirow[t]{2}{*}{ Change in total cholesterol } & & $(n=354)$ & & $(n=362)$ & \\
\hline & & $-0.2(1.0)$ & & $-0.3(1.1)$ & 0.2066 \\
\hline
\end{tabular}


Table 6 continued

\begin{tabular}{|c|c|c|c|c|c|}
\hline \multirow[t]{2}{*}{ Variable } & \multicolumn{2}{|c|}{$\begin{array}{l}\text { Exenatide BID } \\
(n=619)\end{array}$} & \multicolumn{2}{|c|}{ Insulin $(n=619)$} & \multirow[t]{2}{*}{$\begin{array}{l}p \text { value } \\
\text { (change) }\end{array}$} \\
\hline & Baseline & 24 months & Baseline & 24 months & \\
\hline \multirow[t]{2}{*}{ HDL cholesterol } & $(n=542)$ & $(n=358)$ & $(n=527)$ & $(n=361)$ & \\
\hline & $1.2(0.3)$ & $1.2(0.3)$ & $1.2(0.3)$ & $1.2(0.4)$ & - \\
\hline \multirow[t]{2}{*}{ Change in $\mathrm{HDL}$} & & $(n=339)$ & & $(n=338)$ & \\
\hline & & $0.0(0.2)$ & & $0.0(0.3)$ & 0.6591 \\
\hline \multirow[t]{2}{*}{ LDL cholesterol } & $(n=531)$ & $(n=346)$ & $(n=514)$ & $(n=357)$ & \\
\hline & $2.8(0.9)$ & $2.7(0.9)$ & $3.0(1.0)$ & $2.8(0.9)$ & - \\
\hline \multirow[t]{2}{*}{ Change in LDL } & & $(n=327)$ & & $(n=330)$ & \\
\hline & & $-0.1(0.9)$ & & $-0.3(1.0)$ & 0.4268 \\
\hline \multirow[t]{2}{*}{ Triglycerides } & $(n=551)$ & $(n=360)$ & $(n=547)$ & $(n=372)$ & \\
\hline & $2.4(1.6)$ & $1.9(1.2)$ & $2.4(2.0)$ & $1.9(1.1)$ & - \\
\hline \multirow[t]{2}{*}{ Change in triglycerides } & & $(n=344)$ & & $(n=353)$ & \\
\hline & & $-0.4(1.4)$ & & $-0.3(1.5)$ & 0.2045 \\
\hline
\end{tabular}

Continuous data are means (SD); changes were compared between the 2 matched subgroups using paired $t$ tests $B I D$ twice daily, $G I$ gastrointestinal, $H b A_{l c}$ glycated hemoglobin, $H D L$ high-density lipoprotein, $L D L$ low-density lipoprotein, $S D$ standard deviation

${ }^{*} p<0.0001$ versus insulin, McNemar's test

${ }^{a}$ Data from the subgroup of 555 patients in the exenatide BID group and 548 patients in the insulin group with $\mathrm{HbA}_{1 \mathrm{c}}$ $\geq 7.0 \%$ at baseline (144 and 128 patients, respectively, had missing data at 24 months)

b Data from the subgroup of 570 patients in the exenatide BID group and 576 patients in the insulin group with $\mathrm{HbA}_{1 \mathrm{c}}$ $\geq 6.5 \%$ at baseline (149 and 135 patients, respectively, had missing data at 24 months)

${ }^{c}$ Incidence is based on patient recall of events occurring: baseline $=$ past 3 months; 24 months $=$ past 24 months

d Patients with GI symptoms at baseline and those experiencing GI symptoms between baseline and 24 months

discontinuation. Clinicians and reimbursement authorities in the European Union are therefore interested in how long patients remain on exenatide BID before intensifying or discontinuing their therapy, and what treatment changes are made. In addition, guidelines recommend that patients maintain glycemic control [1] because a lack of glycemic control is associated with increased morbidity [14], so the time taken to modify treatment in response to poor control or unwanted adverse effects for patients initiated on exenatide BID or insulin is of interest. We found that the proportion of enrolled patients with treatment change in the exenatide BID group was highest in the first 6 months of the study and then decreased throughout the remainder of the study. The majority of the first significant treatment changes in this cohort were discontinuations, with the remainder mainly comprising the addition of oral antidiabetes medications. The most frequent reasons for treatment change were inadequate response and adverse events. This is consistent with the results of a recently published clinical trial [15]. Post hoc analyses of CHOICE identified 
increased $\mathrm{BMI}$ or $\mathrm{HbA}_{1 \mathrm{c}}$ as factors associated with a switch from exenatide BID to insulin therapy.

In the insulin cohort, the proportions of patients with significant treatment change were also highest in the first 6 months of the study and then decreased throughout the remainder of the study. The most common first significant treatment change for patients on insulin was the addition of a new injectable antidiabetes medication, with most patients requiring upgraded therapy to a more intensive regimen. When compared with baseline initiation of long-acting insulin only, patients initiating basal-bolus insulin or mixtures were less likely to have significant treatment change, and those initiating short-acting insulin only were more likely to have significant treatment change (Fig. 3). These observations are in line with results of the $4 \mathrm{~T}$ trial, which indicated that, after 1 year, patients initially treated only with long-acting insulin were more likely to require a change in treatment (additional dose or addition of a second insulin) than patients initially receiving basal-bolus insulin [16] and, after 3 years, patients initiated only on shortacting or long-acting insulin required higher insulin doses than those initiated on basal-bolus insulin [17]. However, patients initiating only short-acting insulin in the $4 \mathrm{~T}$ trial were less likely to require addition of another type of insulin than patients initiated on long-acting insulin after 1 year [16]. A switch from the initial insulin regimen to another of similar complexity and efficacy was more likely in patients with at least one microvascular diagnosis at baseline, and in patients with an increase in $\mathrm{BMI}$ or $\mathrm{HbA}_{1 \mathrm{c}}$, or who experienced hypoglycemia during treatment with their baseline regimen. However, for both the exenatide BID and insulin cohorts, treatment change could not be directly linked with $\mathrm{HbA}_{1 \mathrm{c}}$ levels reported in this study as treatment changes could have occurred between study time-points, whereas $\mathrm{HbA}_{1 \mathrm{c}}$ measurements were recorded at study visits (i.e., not necessarily at the time of treatment change).

Clinical findings from CHOICE appear consistent when comparing findings from the initiators population (which included patients who had changed treatment), persisters population (which comprised only patients who remained on their initial injectable therapy at study end or study discontinuation) and on-drug population (which comprised all patients from the initiators population up to the time of any switch of treatment or discontinuation of the initial injectable therapy; data not shown). They are also in line with findings from RCTs [18-20] and other observational studies [21-24], although comparability of the primary analyses (the 'initiators' analyses) with findings from other studies is limited by the fact that patients could be started on an alternative treatment while remaining in CHOICE. The demographics and characteristics of the patients from CHOICE who were initiated on exenatide BID were consistent with those of patients from the Exenatide BID Observational Study (ExOS) conducted in the United States [21, 22]. The Association of British Clinical Diabetologists' nationwide exenatide audit, which was performed in the United Kingdom, included patients who were broadly similar to our population, except that their mean baseline $\mathrm{HbA}_{1 \mathrm{c}}$ was higher $(9.47 \%)$ than in our study, and $33.9 \%$ of patients in their study were also receiving insulin at the time exenatide was initiated [24]. In the US study, which was singlearm and included patients initiated on exenatide BID, irrespective of previous insulin use, significant improvements were observed after 12 months in $\mathrm{HbA}_{1 \mathrm{c}}(-0.80 \%)$, weight 
$(-2.4 \mathrm{~kg})$, and BMI $\left(-0.83 \mathrm{~kg} / \mathrm{m}^{2} ; p \leq 0.0001\right.$ for all) $[21,22]$. The UK audit of patients recently started on exenatide also revealed clinical improvements after a median of 6 months of exenatide therapy (the regimen was not described), with reported decreases of $0.73 \%$ for $\mathrm{HbA}_{1 \mathrm{c}}, 5.9 \mathrm{~kg}$ for weight, and $2.2 \mathrm{~kg} / \mathrm{m}^{2}$ for BMI $(p<0.001$ for all) [24]. Another study that used a real-world setting to evaluate the effectiveness of exenatide BID was the retrospective claims database audit of Brixner et al. [23]. Patients who were included in this latter analysis were selected according to the exenatide BID label [25] and had data for the first 6 months after initiation of exenatide BID. Clinical improvements in this study were again consistent with our findings and those reported in the other studies discussed here. However, these studies have certain limitations in that all were of relatively short duration (6 or 12 months) and were either single-arm or retrospective in design. When compared with prospective observational studies evaluating initial use of insulin, 24-month results of the INSTIGATE study showed that in three European countries, $23.9 \%$ of patients changed their insulin regimen (which was initiated at the discretion of the treating physician) and patients achieved similar reductions in $\mathrm{HbA}_{1 \mathrm{c}}$ as are reported in our study [26]. In CHOICE, $\mathrm{HbA}_{1 \mathrm{c}}$ was reduced by $1.0 \%$ units in the exenatide BID cohort and $1.7 \%$ units in the insulin cohort, although the change is likely confounded by the higher baseline $\mathrm{HbA}_{1 \mathrm{c}}$ in the insulin cohort.

There has recently been a move toward comparative effectiveness research and the desire to compare therapies in clinical practice $[1,27]$. Although CHOICE was not designed to do this, a matched subgroup of patients, including approximately half the study population, was identified using propensity score data. Analyses conducted in these patients did not demonstrate a difference between the exenatide BID group and the insulin group in mean changes in $\mathrm{HbA}_{1 \mathrm{c}}$, and percentages of patients at 24 months with $\mathrm{HbA}_{1 \mathrm{c}}<7.0 \%$ or $<6.5 \%$. However, patients in the exenatide BID-matched group had significantly greater mean weight loss $(p<0.0001)$ and a lower incidence of patientrecalled hypoglycemia $(p<0.0001)$ than the insulin-matched group during the study. These findings are consistent with the results of RCTs comparing GLP-1 receptor agonists and insulin therapy [2-4, 28-30]. Although the incidence of hypoglycemia relied on patient recall and was not measured objectively in CHOICE, these episodes may better reflect patient-relevant hypoglycemia (i.e., those episodes that may have caused anxiety or concern, or had an impact on behavior or the self-management of diabetes). In our study, $26.9 \%$ of patients in the exenatide BID-matched subgroup achieved the clinically relevant composite endpoint of $\mathrm{HbA}_{1 \mathrm{c}}$ $<7.0 \%$, no weight gain ( $\leq 1 \mathrm{~kg}$ change), and no hypoglycemia at 24 months. This compares with $40 \%$ of liraglutide $1.8 \mathrm{mg}$ and $32 \%$ of liraglutide $1.2 \mathrm{mg}$ recipients achieving this endpoint according to the meta-analysis of Zinman et al. [12]. However, these results for liraglutide were achieved at 26 weeks in RCTs, whereas our findings were obtained after a considerably longer duration of treatment and in a prospective, observational manner. These findings, along with the requirement for glucose monitoring and limited flexibility in lifestyle to avoid hypoglycemia with insulin, support the preferential use of GLP-1 receptor agonists over insulin in selected patients, such as those requiring weight loss or who are at risk of hypoglycemia, as is recommended [1].

Prospective observational studies have certain limitations, including the unknown 
magnitude of observer effects, the potential for investigators to be influenced by the scrutiny that occurs during a prospective study, and the potential for selection bias. The inclusion of two treatment cohorts is anticipated to have helped reduce prescribing bias, as is the fact that patients were invited to participate in our study only after the clinical decision had been made to initiate exenatide BID or insulin. This inclusion criterion also avoided several additional problems identified with some observational studies, such as their propensity to change the prescribing habits of the participating physicians [31, 32].

Although the sample was designed to be representative, recruitment targets were prespecified, sample sizes were small in some countries, the ratio of exenatide BID to insulin patients varied between countries, and patients were mostly recruited in secondary care centers.

The CHOICE study has provided the first available data on the use of exenatide BID in routine clinical practice across Europe. It is likely that treatment patterns have changed since this study was conducted. Additional GLP1 receptor agonist therapies are now available (exenatide once weekly and liraglutide, for instance) and in March 2012, exenatide BID received EU approval as adjunctive therapy in adult patients with T2DM who have not achieved adequate glycemic control with basal insulin, with or without metformin and/or pioglitazone [33]. The latter was not an approved indication for exenatide BID for the duration of CHOICE, and only two patients from the insulin cohort were initiated on this agent during the study. However, we expect that this new indication for exenatide BID may have a substantial impact on prescribing trends for patients with T2DM, as UK-based audits have shown that between $30 \%$ and $40 \%$ of the patients initiated on GLP-1 receptor agonists before this indication was approved were also receiving basal insulin concomitantly [24, 34].

\section{CONCLUSION}

In addition to estimating the time to first significant treatment change and evaluating reasons for the treatment change following initiation of injectable therapy, CHOICE provided data on exenatide BID usage patterns and 24-month outcomes in clinical practice. Results show that $42.2 \%$ of patients initiated on exenatide BID and $36.0 \%$ of those initiated on insulin as their first injectable glucose-lowering therapy had a significant treatment change during the first 24 months of therapy. Nevertheless, patients in both treatment cohorts achieved improved glycemic control and a reduced severity of cardiovascular risk factors, and those in the exenatide BID cohort also achieved mean weight loss. These findings for exenatide BID were consistent with results reported from RCTs.

\section{ACKNOWLEDGMENTS}

The study and the development of this manuscript were sponsored by Eli Lilly and Amylin Pharmaceuticals, LLC. The authors would like to acknowledge Caroline Spencer (Rx Communications, Mold, UK) for medical writing assistance with the preparation of this article, funded by Eli Lilly, and Simon Cleall (Eli Lilly, Windlesham, UK) for statistical advice. Prof. Chantal Mathieu is the guarantor for this article, and takes responsibility for the integrity of the work as a whole.

Conflict of interest. Chantal Mathieu is an advisory board member for Lilly Belgium. Thure Krarup is an advisory board member 
for Lilly Denmark. Stephan Matthaei and Bruno Guerci have received honoraria from Eli Lilly for lectures and consultancy. Claes-Göran Östenson has received honoraria from Eli Lilly for consultancy. Matthew Reaney and Hélène Sapin are employees of Eli Lilly but are not shareholders. Jacek Kiljański and Carole Salaun-Martin are employees of Eli Lilly and holders of Eli Lilly shares and share options. Michael Theodorakis declares no conflict of interest.

Compliance with ethics guidelines. Patients gave written informed consent for the use of their data and appropriate ethical review board approval was obtained.

Open Access. This article is distributed under the terms of the Creative Commons Attribution Noncommercial License which permits any noncommercial use, distribution, and reproduction in any medium, provided the original author(s) and the source are credited.

\section{APPENDIX}

See Table 7.

Table 7 Examples of switch, upgrade, downgrade and discontinuation of insulin therapy according to the alternative definition of treatment change

\begin{tabular}{lll}
\hline Baseline regimen & New regimen & Treatment change \\
\hline Basal analog insulin & NPH & Switch \\
Basal analog insulin & Prandial only, pre-mix & Upgrade \\
NPH & Basal analog insulin & Switch \\
NPH & Prandial only, pre-mix & Upgrade \\
Pre-mix & Basal/NPH only, prandial only, & Downgrade \\
Pre-mix & Basal-bolus & Upgrade \\
Prandial analog insulin & Basal/NPH only & Downgrade \\
Prandial analog insulin & Prandial human insulin & Switch \\
Prandial human insulin & Basal/NPH only & Downgrade \\
Prandial human insulin & Pre-mix & Upgrade \\
Prandial analog insulin & Pre-mix & Upgrade \\
Prandial human insulin & Prandial analog insulin & Switch \\
Basal-bolus & Basal/NPH only, prandial only, pre-mix & Downgrade \\
Basal-bolus (human and/or analog) & Basal-bolus (analog and/or human) & Switch \\
Any regimen & No regimen started within 30 days & Discontinuation \\
Any regimen & Same insulin regimen, oral antidiabetes drug & Other \\
\hline
\end{tabular}

$N P H$ neutral protamine hagedorn 


\section{REFERENCES}

1. Inzucchi SE, Bergenstal RM, Buse JB, et al. Management of hyperglycaemia in type 2 diabetes: a patient-centered approach. Position statement of the American Diabetes Association (ADA) and the European Association for the Study of Diabetes (EASD). Diabetologia. 2012;55:1577-96.

2. Barnett AH, Burger J, Johns D, et al. Tolerability and efficacy of exenatide and titrated insulin glargine in adult patients with type 2 diabetes previously uncontrolled with metformin or a sulfonylurea: a multinational, randomized, open-label, two-period, crossover noninferiority trial. Clin Ther. 2007;29:2333-48.

3. Heine RJ, Van Gaal LF, Johns D, et al. Exenatide versus insulin glargine in patients with suboptimally controlled type 2 diabetes: a randomized trial. Ann Intern Med. 2005;143:559-69.

4. Nauck MA, Duran S, Kim D, Johns D, Northrup J, Festa A. A comparison of twice-daily exenatide and biphasic insulin aspart in patients with type 2 diabetes who were suboptimally controlled with sulfonylurea and metformin: a non-inferiority study. Diabetologia. 2007;50:259-67.

5. Dreyer NA, Tunis SR, Berger M, Ollendorf D, Mattox $\mathrm{P}$, Gliklich R. Why observational studies should be among the tools used in comparative effectiveness research. Health Aff (Millwood). 2010;10:1818-25.

6. Ware JH, Hamel MB. Pragmatic trials-guides to better patient care? N Engl J Med. 2011;364:1865-7.

7. Ligthelm RJ, Borzì V, Gumprecht J, Kawamori R, Wenying Y, Valensi P. Importance of observational studies in clinical practice. Clin Ther. 2007;29 Spec No:1284-92.

8. Mann CJ. Observational research methods. Research design II: cohort, cross sectional, and case-control studies. Emerg Med J. 2003;20:54-60.

9. Matthaei S, Reaney M, Mathieu C, et al. Patients with type 2 diabetes initiating exenatide BID or insulin in clinical practice: CHOICE study. Diabetes Ther. 2012;3:6.

10. Jones S, Benroubi M, Castell C, et al. Characteristics of patients with type 2 diabetes mellitus initiating insulin therapy: baseline data from the INSTIGATE study. Curr Med Res Opin. 2009;25:691-700.

11. Yue LQ. Statistical and regulatory issues with the application of propensity score analysis to nonrandomized medical device clinical studies. J Biopharm Stat. 2007;17:1-13.
12. Zinman B, Schmidt WE, Moses A, et al. Achieving a clinically relevant composite outcome of an $\mathrm{HbA}_{1 \mathrm{c}}$ of $<7 \%$ without weight gain or hypoglycaemia in type 2 diabetes: a meta-analysis of the liraglutide clinical trial programme. Diabetes Obes Metab. 2012;14:77-82.

13. Benroubi M, Schmitt $\mathrm{H}$, Cleall SP, et al., TREAT Study Investigators. Costs and clinical outcomes after 24 months of insulin therapy in patients with type 2 diabetes: results from the TREAT study. Poster presented at the 47th European Association for the Study of Diabetes (EASD) Annual Meeting, Lisbon, Portugal, 12-16 September 2011.

14. Stratton IM, Adler AI, Neil HA, et al. Association of glycaemia with macrovascular and microvascular complications of type 2 diabetes (UKPDS 35): prospective observational study. BMJ. 2000;321:405-12.

15. Gallwitz B, Guzman J, Dotta F, et al. Exenatide twice daily versus glimepiride for prevention of glycaemic deterioration in patients with type 2 diabetes with metformin failure (EUREXA): an open-label, randomised controlled trial. Lancet. 2012;379:2270-8.

16. Holman RR, Thorne KI, Farmer AJ, 4-T Study Group, et al. Addition of biphasic, prandial, or basal insulin to oral therapy in type 2 diabetes. N Engl J Med. 2007;357:1716-30.

17. Holman RR, Farmer AJ, Davies MJ, 4-T Study Group, et al. Three-year efficacy of complex insulin regimens in type 2 diabetes. $\mathrm{N}$ Engl J Med. 2009;361:1736-47.

18. DeFronzo RA, Ratner RE, Han J, Kim DD, Fineman MS, Baron AD. Effects of exenatide (exendin-4) on glycemic control and weight over 30 weeks in metformin-treated patients with type 2 diabetes. Diabetes Care. 2005;28:1092-100.

19. Buse JB, Henry RR, Han J, Exenatide-113 Clinical Study Group, et al. Effects of exenatide (exendin-4) on glycemic control over 30 weeks in sulfonylureatreated patients with type 2 diabetes. Diabetes Care. 2004;27:2628-35.

20. Kendall DM, Riddle MC, Rosenstock J, et al. Effects of exenatide (exendin-4) on glycemic control over 30 weeks in patients with type 2 diabetes treated with metformin and a sulfonylurea. Diabetes Care. 2005;28:1083-91.

21. Bergenstal RM, Garrison LP, Miller LA, et al. Exenatide BID Observational Study (ExOS): results for primary and secondary endpoints of a prospective research study to evaluate the clinical effectiveness of exenatide BID use in patients with 
type 2 diabetes in a real-world setting. Curr Med Res Opin. 2011;27:2335-42.

22. Bergenstal RM, Garrison LP Jr, Wintle M, et al. Exenatide bid observational study (ExOS): baseline population characteristics of a prospective research study to evaluate the clinical effectiveness of exenatide bid use in patients with type 2 diabetes in a real-world setting. Curr Med Res Opin. 2011;27:531-40.

23. Brixner DI, McAdam-Marx C, Ye X, et al. Six-month outcomes on A1C and cardiovascular risk factors in patients with type 2 diabetes treated with exenatide in an ambulatory care setting. Diabetes Obes Metab. 2009;11:1122-30.

24. Ryder REJ, Thong KY, Cull ML, et al., ABCD Nationwide Exenatide Audit Contributors. The Association of British Clinical Diabetologists (ABCD) nationwide exenatide audit. Pract Diab Int. 2010;27:352-7.

25. Exenatide injection [package insert]. San Diego: Amylin Pharmaceuticals, Inc; 2011.

26. Liebl A, Jones S, Goday A, et al. Clinical outcomes after insulin initiation in patients with type 2 diabetes: 24-month results from INSTIGATE. Diabetes Ther. 2012;3:9.

27. Bennett WL, Balfe LM, Faysal JM. AHRQ's comparative effectiveness research on oral medications for type 2 diabetes: a summary of the key findings. J Manag Care Pharm. 2012;18(1 Suppl. A):1-22.

28. Russell-Jones D, Vaag A, Schmitz O, Liraglutide effect and action in Diabetes 5 (LEAD-5) met + SU
Study Group, et al. Liraglutide vs insulin glargine and placebo in combination with metformin and sulfonylurea therapy in type 2 diabetes mellitus (LEAD-5 met $+\mathrm{SU})$ : a randomised controlled trial. Diabetologia. 2009;52:2046-55.

29. Diamant M, Van Gaal L, Stranks S, et al. Once weekly exenatide compared with insulin glargine titrated to target in patients with type 2 diabetes (DURATION-3): an open-label randomised trial. Lancet. 2010;375:2234-43.

30. Waugh N, Cummins E, Royle P, et al. Newer agents for blood glucose control in type 2 diabetes: systematic review and economic evaluation. Health Technol Assess. 2010;14:1-248.

31. Gale EA. Post-marketing studies of new insulins: sales or science? BMJ. 2012;344:e3974.

32. Yudkin JS. Post-marketing observational trials and catastrophic health expenditure. BMJ. 2012;344: e3987.

33. Byetta approved for use with basal insulin in Europe (press release). San Diego, CA: Amylin Pharmaceuticals, Inc. c2012 (updated March 23, 2012; cited June 13, 2012). https://investor.lilly. $\mathrm{com} /$ releasedetail2.cfm?ReleaseID=659089. Accessed 12 Dec 2012.

34. Ryder RJ, Thong K, ABCD Nationwide Exenatide and Liraglutide Audit Contributors. ABCD Nationwide Exenatide and Liraglutide Audits. Oral presentation at the diabetes UK annual professional conference, London, 30 March-1 April 2011. 